\title{
Preovulatory follicle growth dynamics indicates daily spawning synchronicity in wild-caught Atlantic horse mackerel off Portugal
}

\author{
Foivos Alexandros Mouchlianitis ${ }^{1, a}$, Cristina Nunes ${ }^{2}$, Ana Maria Costa $^{2}$, Maria Manuel Angélico ${ }^{2}$ and \\ Konstantinos Ganias ${ }^{1, a, *}$ \\ ${ }^{1}$ School of Biology, Aristotle University of Thessaloniki, AUTH, Thessaloniki, Greece \\ 2 Instituto Português do Mar e da Atmosfera, IPMA, Lisbon, Portugal
}

Received 28 August 2017 / Accepted 24 December 2017

Handling Editor: Mohamed Salah Romdhane

\begin{abstract}
The Atlantic horse mackerel, Trachurus trachurus, is a commercially important species whose daily spawning dynamics are not yet fully understood. Existence of spawning synchronicity would facilitate application of the daily egg production method for estimating the spawning biomass of the southern stock of the species in the Northeast Atlantic. The intent of this work was to study preovulatory follicle (PREF) growth dynamics in wild Atlantic horse mackerel to determine the existence of daily spawning synchronicity in the population. The size and translucency of hydrated oocytes increased significantly between early morning and late afternoon; this pattern was the same for two study years. This morphodevelopmental shift led to the appearance of previously indistinguishable oil drops in ovarian whole mounts which is an easily observed microscopic descriptor of PREF growth. The results clearly suggested that PREF growth was well synchronized between Atlantic horse mackerel that were capable of spawning and provided evidence for the existence of daily spawning synchronicity in the population. Apart from sampling time of day, the size of hydrated oocytes was shown to be affected by body size: a $10 \mathrm{~cm}$ difference in maternal length corresponded to a $0.030 \mathrm{~mm}$ difference in the diameter of hydrated oocytes. In contrast, the size of early germinal vesicle migration oocytes was correlated neither to sampling time nor to maternal size which suggests that the abrupt increase in PREF size only commences after the onset of the actively spawning sub-phase.
\end{abstract}

Keywords: Trachurus trachurus / daily spawning synchronicity / daily egg production method / preovulatory follicles / oocyte size

\section{Introduction}

Ovarian development in fish occurs over different temporal scales (lifetime, annual, seasonal, diel; Lowerre-Barbieri et al., 2011), while follicular development is typically divided into a primary and secondary growth phase which in turn is subdivided into the cortical alveolar stage, the various stages of vitellogenesis and final oocyte maturation (FOM) (Lubzens et al., 2010; Brown-Peterson et al., 2011). In many fish species, particularly in marine species with pelagic eggs, FOM ends with hydration which is a cytoplasmic event that causes a major and swift uptake of fluid by the oocytes and thus makes them swollen and buoyant in sea water, allowing their survival and dispersal at sea (Wallace and Selman, 1981; Thorsen and Fyhn, 1996).

\footnotetext{
*Corresponding author: kganias@bio.auth.gr

${ }^{\mathrm{a}}$ These authors contributed equally to this work.
}

Hydration is a preovulatory process which typically occurs at the diel scale, affecting the probability of fertilization and the dispersion of the fertilized eggs and larvae, and the rate of predation (Yamahira, 2001; Gladstone, 2007).

For assessment purposes, preovulatory stages are important because they can be used for measuring batch fecundity (e. g. using the hydrated oocytes method; Hunter et al., 1985), as estimators of spawning frequency (DeMartini and Fountain, 1981; Priede and Watson, 1993), or for assessing fish reproductive phenomena such as the formation of spawning aggregations and courtship behaviour (Alheit, 1985; Ganias, 2008). In routine assessments of wild fish specimens, as needed for the applications of the daily egg production method (DEPM), preovulatory stages are mainly used together with running females - those caught during the spawning act, containing both hydrated oocytes and early postovulatory follicles (POFs) - and early postovulatory stages in order to describe the daily spawning pattern of the population 
(e.g. Basilone et al., 2015). The latter is rather important for the application of the DEPM because synchronicity of spawning and estimation of mean spawning time are very helpful both for the ageing of POFs and the ageing of eggs for subsequent estimation of the spawning fraction and the daily egg production, respectively (Stratoudakis et al., 2006).

Despite its importance, the running stage is rarely observed or even absent in sampled wild fish specimens (Basilone et al., 2015), mainly due to the limited duration of ovulation and spawning (Alheit, 1985; Hunter et al., 1985) while postovulatory stages are difficult to assess (Ganias, 2012). Preovulatory stages, on the other hand, are commonly observed in samples originating from spawning aggregations (Ganias, 2008). Further, their macroscopic identification is quite easy, especially for the hydration stage, in contrast to running and postovulatory stages which can only be identified histologically. Despite the ease of use, preovulatory stages have seldom been used for the study of diel spawning dynamics of fish populations. Variability in the weight of hydrated ovaries (Zwolinski et al., 2001) and in the growth patterns of hydrated oocytes (Ganias et al., 2011) have been used however to assess the daily spawning patterns of sardine off the Iberian peninsula. Both papers suggested synchronization of FOM amongst imminent spawners which helped elucidating the daily spawning pattern of the population (Bernal et al., 2011) and disentangling maternal effects on egg size (Ganias et al., 2015).

The Atlantic horse mackerel, Trachurus trachurus, is a commercially important species, whose biomass has been estimated applying the egg production methods for almost 30 years (Gordo et al., 2008; Van Damme et al., 2014). Since 2007 the DEPM is being applied to the southern stock (ICES, 2008, 2012, 2017; Gonçalves et al., 2009). Ovarian dynamics in Atlantic horse mackerel have been studied in terms of fecundity, spawning fraction and spawning period, fecundity type and regulation, both in the wild (Macer, 1974; KarlouRiga and Economidis, 1996, 1997; Abaunza et al., 2003; Van Damme et al., 2005; Gonçalves et al., 2009; Ganias et al., 2017) and in captivity (Ndjaula et al., 2009). However, daily spawning dynamics are not yet fully understood. Some studies argued that the daily spawning period of horse mackerel is not well known (e.g. Gonçalves et al., 2009; Murta and Vendrell, 2009), while others presumed that the species exhibits daily spawning synchronicity, hence POFs' ageing and spawning fraction estimation are feasible (Abaunza et al., 2003). However, none of these previous studies focused on elucidating the daily spawning pattern of horse mackerel. Most information about spawning patterns comes from other Trachurus species. Farris (1961) suggested that maximum spawning for jack mackerel, Trachurus symmetricus, occurred approximately at midnight by plotting the relative abundance of pre-cleavage eggs against time of day of specimen collection. Thus, an assessment of the diel spawning dynamics of Atlantic horse mackerel is timely and essential, having direct implications for the efficient application of the DEPM and the valid estimation of horse mackerel spawning stock biomass.

The main objective of this work was to study preovulatory follicle (PREF) growth dynamics in wild specimens of Atlantic horse mackerel and examine the existence of daily spawning synchronicity in the population. To do this we analysed the hourly evolution of oocyte size in preovulatory stages. This type of analysis further allows investigating the effect of additional predictors of preovulatory oocyte size such as year or body size (e.g. Ganias et al., 2015). An additional aim was to investigate possible critical developmental phases and microscopic descriptors during the hydration of Atlantic horse mackerel oocytes that could enhance the elucidation of its daily spawning pattern.

\section{Materials and methods}

Adult Atlantic horse mackerel samples were collected in 2010 and 2013 (28th January-3rd March and 9th-22nd February, respectively) in western and southern Atlantic Iberian waters, during IPMA's (Instituto Português do Mar e da Atmosfera) surveys (Fig.1). Sampling was conducted during the spawning season. In 2010, fish samples were obtained both on board RV "Noruega" and from the bottom trawl commercial fleet, whereas in 2013 samples were provided only by commercial vessels. Immediately (research samples) or a few hours (commercial samples) after capture fish were sampled, measured for total length (TL, cm), ovaries were dissected and fixed in $10 \%$ neutral buffered formalin (NBF) and then transferred to the laboratory where they were stored, again in NBF.

In the laboratory, the preserved ovaries were processed both histologically, using standard procedures (paraffin embedding; $4 \mu \mathrm{m}$ sections; haematoxylin/eosin staining), and gravimetrically (whole mount procedures). Histological slides were examined and scored for the most advanced stage of oocytes present in the ovary, according to criteria and terminology of Brown-Peterson et al. (2011). The present study strictly focused on preovulatory stages, from the early germinal vesicle migration stage (EGVM; Fig. 2A and C) up to hydration (HYD; Fig. 2B and D). In addition, the selection of specimens was performed so as to get the widest possible range of hours of the day sampled (Tab. 1). A total of 141 ovaries were selected for the present study.

The late germinal vesicle migration (LGVM) stage was not found while the germinal vesicle breakdown stage (GVBD) was only found in two females caught around midnight (Tab. 1). For analysis purposes, the GVBD stage was merged with the HYD stage supposing that both are stages of the actively spawning sub-phase (Brown-Peterson et al., 2011). In addition, whole mounts of hydrated ovaries, stored also in NBF, were subjected to detailed microscopic observations to investigate possible morpho-developmental markers.

The initial phase of whole mount processing was the same for both EGVM and HYD ovaries and briefly consisted of: (a) washing the whole mount into $0.150 \mathrm{~mm}$ mesh sieve to discard the very small, mainly primary growth, oocytes which were not useful for the analysis, (b) processing the tissue under a stereo-microscope (Olympus SZX9) to separate oocytes and spread them in a mono-layer, and (c) capturing the whole mount at $8 x$ magnification with a camera (Sony DFW-SX910) fitted to the stereo-microscope using transmitted light illumination. All ovary sub-samples were processed in isotonic solution and were photographed at maximum 15 min after ovary dissection (Ganias et al., 2017). Oocytes in each image were then measured for their diameters using 


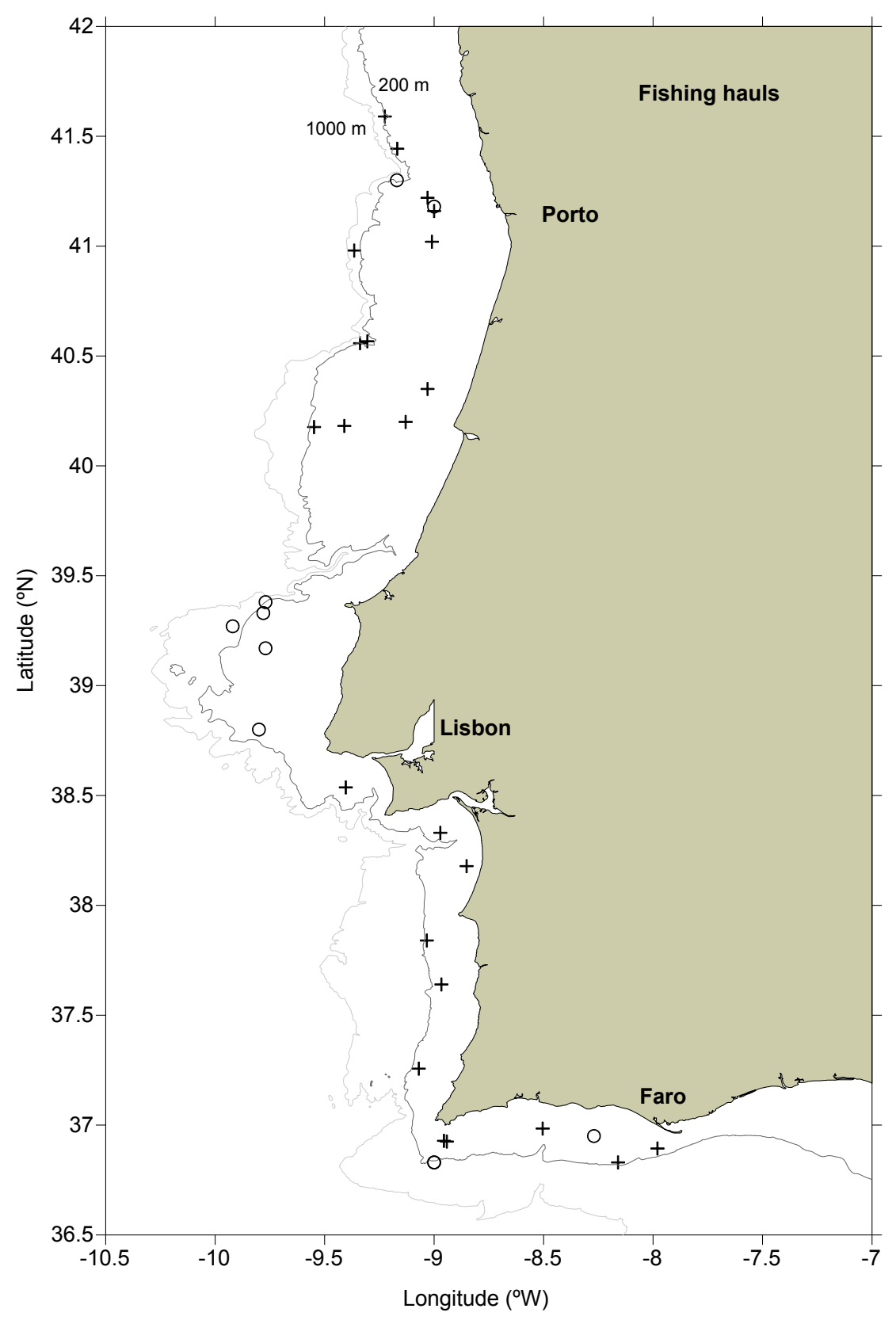

Fig. 1. Map of the survey area showing the sampling locations of adult Atlantic horse mackerel samples for 2010 (crosses) and 2013 (open circles).

particle analysis (Thorsen and Kjesbu, 2001). Ganias et al. (2017) found that the spawning batch in Atlantic horse mackerel may only be discerned and enumerated at the hydration stage and not at previous stages - such as GVM similar to other batch spawners (e.g. Atlantic sardine, Ganias et al., 2011). Therefore, subsequent processing was different for EGVM and HYD ovaries. For HYD ovaries the size $\left(\mathrm{OD}_{\mathrm{HYD}}\right)$ of all hydrated oocytes of the micrograph was measured directly (the minimum size of hydrate oocytes is $0.65 \mathrm{~mm}$; see Fig. 5B in Ganias et al., 2017). For EGVM ovaries, oocyte size measurements $\left(\mathrm{OD}_{\mathrm{EGVM}}\right)$ corresponded to the mode of oocytes that ranged between 0.500 and $0.650 \mathrm{~mm}$ (Ganias et al., 2017).
Oocyte diameter data were modelled as a function of the time of day of capture using generalized linear models (GLMs). Two different GLMs were constructed, one for the oocyte size data for HYD ovaries and one for EGVM ovaries. In both models, TL was used as a covariate to account for changes in OD due to female size. The type of fishery (experimental vs. commercial) was used as a factorial variable, while sampling year (2010 vs. 2013) was only used in the HYD model, since no EGVM females were available in 2013 (Tab. 1). The type of fishery was tested to elucidate a possible effect of the time elapsed between sampling and fixation. In both GLMs, model diagnostics, including plotting residual versus predictions and quantile plots, suggested a Gaussian error structure and an identity link 


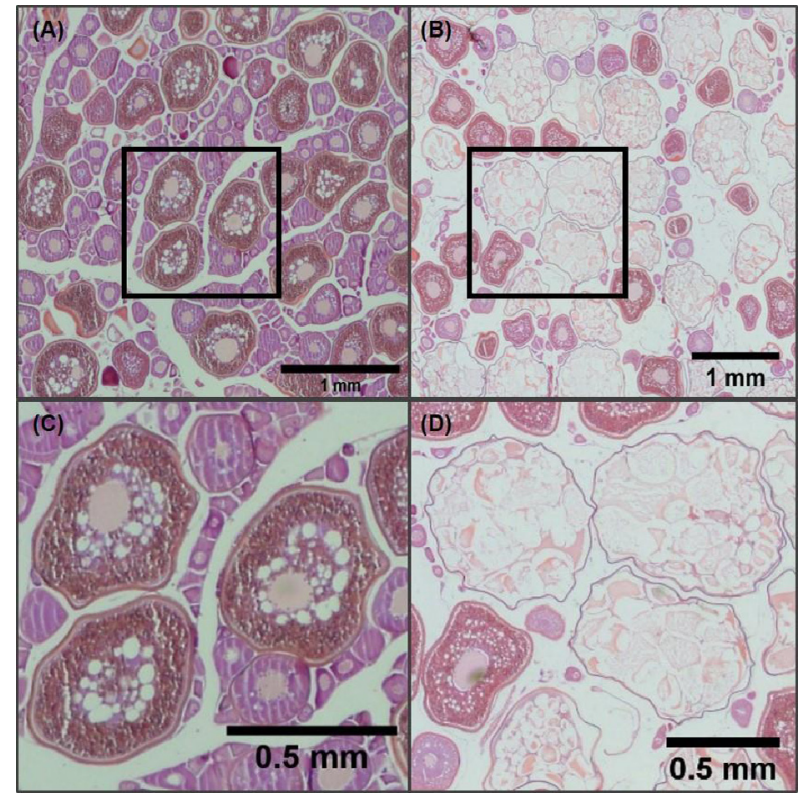

Fig. 2. Expanded (upper panel) versus magnified (lower panel) images of Atlantic horse mackerel, Trachurus trachurus, ovarian cross-sections at early germinal vesicle migration (A and $\mathrm{C}$ ) and hydration stage (B and D). Squares indicate the position of magnified images.

Table 1. Number of early germinal vesicle migration (EGVM) and hydrated (HYD) female Atlantic horse mackerels, Trachurus trachurus, sampled per hour in 2010 and 2013. The total length (TL) range is shown in brackets.

\begin{tabular}{|c|c|c|c|}
\hline \multirow[t]{2}{*}{ Time of day } & \multicolumn{2}{|c|}{2010} & \multirow{2}{*}{$\begin{array}{l}2013 \\
\text { HYD }\end{array}$} \\
\hline & EGVM & HYD & \\
\hline 00:00-1:00 & - & - & $3^{*}(21-22 \mathrm{~cm})$ \\
\hline 7:00-8:00 & $3(23-26 \mathrm{~cm})$ & $5(24-28 \mathrm{~cm})$ & - \\
\hline $8: 00-9: 00$ & $8(24-34 \mathrm{~cm})$ & $9(23-30 \mathrm{~cm})$ & $3(29-31 \mathrm{~cm})$ \\
\hline $9: 00-10: 00$ & $3(29-32 \mathrm{~cm})$ & $2(30-31 \mathrm{~cm})$ & $4(28-32 \mathrm{~cm})$ \\
\hline $11: 00-12: 00$ & $3(22-25 \mathrm{~cm})$ & $18(21-28 \mathrm{~cm})$ & $1(25-26 \mathrm{~cm})$ \\
\hline $12: 00-13: 00$ & $2(27-28 \mathrm{~cm})$ & 0 & - \\
\hline $13: 00-14: 00$ & $7(22-28 \mathrm{~cm})$ & $2(23-24 \mathrm{~cm})$ & $2(25-37 \mathrm{~cm})$ \\
\hline $14: 00-15: 00$ & $16(20-36 \mathrm{~cm})$ & $15(21-29 \mathrm{~cm})$ & - \\
\hline $15: 00-16: 00$ & $1(25-26 \mathrm{~cm})$ & 0 & $8(30-34 \mathrm{~cm})$ \\
\hline $16: 00-17: 00$ & $14(21-34 \mathrm{~cm})$ & 0 & $2(27-31 \mathrm{~cm})$ \\
\hline $17: 00-18: 00$ & $6(31-34 \mathrm{~cm})$ & $2(27-32 \mathrm{~cm})$ & $2(30-33 \mathrm{~cm})$ \\
\hline Total & $63(20-36 \mathrm{~cm})$ & $53(21-32 \mathrm{~cm})$ & $25(21-37 \mathrm{~cm})$ \\
\hline
\end{tabular}

${ }^{*}$ Two out of three HYD individuals sampled between 00:00-01:00 in 2013 were at the germinal vesicle break down stage, but for analysis purposes were merged with the HYD stage.

function. The selection of the appropriate covariates was performed by stepwise (backward) selection using Akaike information criterion adjusted for small sample size $\left(\mathrm{AIC}_{\mathrm{c}}\right)$.

\section{Results}

A total of 78 HYD ovaries (53 from 2010 and 25 from 2013) and 63 EGVM ovaries (only from 2010) were used in the analysis (Tab. 1). The mean diameter of hydrated oocytes in HYD ovaries, $\mathrm{OD}_{\mathrm{HYD}}$, was $0.908 \mathrm{~mm}(\mathrm{~min}=0.723 \mathrm{~mm}$; $\max =$ $1.013 \mathrm{~mm}$ ) while in the two GVBD ovaries the diameter was $0.577 \mathrm{~mm}$ and $0.592 \mathrm{~mm}$. The mean diameter of advanced mode oocytes in EGVM ovaries, $\mathrm{OD}_{\mathrm{EGVM}}$, was $0.557 \mathrm{~mm}(\mathrm{~min}=$ $0.505 \mathrm{~mm} ; \max =0.596 \mathrm{~mm}$ ). The time of day of capture ranged between 00:20 and 17:30 (2010: 07:20-17:30; 2013: 00:20 17:30) while TL, ranged between 20.5 and $36.5 \mathrm{~cm}$ (mean 2010: $26.2 \mathrm{~cm}$; mean 2013: $30.1 \mathrm{~cm}$ ).

Microscopic observations of whole mounts from HYD ovaries revealed a clear morphological shift in the opacity of hydrated oocytes from highly opaque to translucent during the day (Fig. 3). Increasing translucency was accompanied by the appearance of previously indistinguishable oil drops in the ooplasm. In histological specimens, smaller oil droplets were also present in pre-vitellogenic and vitellogenic oocytes (Fig. $2 \mathrm{~A}$ and $\mathrm{C}$ ) while in the whole mounts they were only visible in semi- to highly translucent hydrated oocytes (Fig. 3E and F). Based on this characteristic, ovaries were grouped into two categories: those with distinct oil drops (DRP) and those with no apparent oil drops (NDRP). The observed increase in the translucency and the resulting visibility of oil drops in Atlantic horse mackerel were also clearly related to an increase in hydrated oocyte size, with the mean oocyte diameter of DRP hydrated oocytes being significantly larger than the mean oocyte diameter of NDRP hydrated oocytes (Fig. 4).

Figure 5 shows the relationship between the proportion of hydrated individuals with DRP and time of day of sampling. A clear temporal pattern was observed with DRP individuals prevailing from noon onwards. This pattern was consistent across years. The change in the proportion of DRP individuals with time of day was analysed using a GLM with binomial error distribution and a logit link. The analysis showed no statistical difference between the two years (Fig. $5 ; P>0.1$ ), with the critical time of day for the NDRP to DRP transition the time where $50 \%$ of HYD females where at the DRP stage estimated at around 11:00 a.m. (UTC).

PREF dynamics were explored through modelling the mean diameters of oocytes in HYD and EGVM ovaries as a function of time of day, body size, fishery type and sampling year. Only time of day and body size were significant for HYD ovaries explaining $52 \%$ of deviance (Tab. 2; Fig. 6). None of the variables explained any variation in oocyte diameter for EGVM ovaries. For an average HYD female of $30 \mathrm{~cm}, \mathrm{OD}_{\mathrm{HYD}}$ was found to increase by $0.010 \mathrm{~mm}$ per hour, meaning that during the sampled time of day range $\mathrm{OD}_{\mathrm{HYD}}$ increased from $0.884 \mathrm{~mm}$ at 07:00 a.m. to $0.97 \mathrm{~mm}$ at $18: 00 \mathrm{p} . \mathrm{m}$. Assuming a time of capture at noon $(12: 00), \mathrm{OD}_{\mathrm{HYD}}$ was found to increase by $0.003 \mathrm{~mm}$ per $1 \mathrm{~cm}$ of TL. Therefore, for the TL range of the present study, $\mathrm{OD}_{\mathrm{HYD}}$ increased from $0.90 \mathrm{~mm}$ at $20 \mathrm{~cm}$ to $0.95 \mathrm{~mm}$ at $35 \mathrm{~cm}$.

\section{Discussion}

The present study by investigating PREF growth dynamics in wild collections of Atlantic horse mackerel found clear evidence for daily spawning synchronicity. As highlighted in the introduction, such study has never been undertaken neither in the field nor in captivity despite the number of DEPM applications for the southern stock of Atlantic horse mackerel 


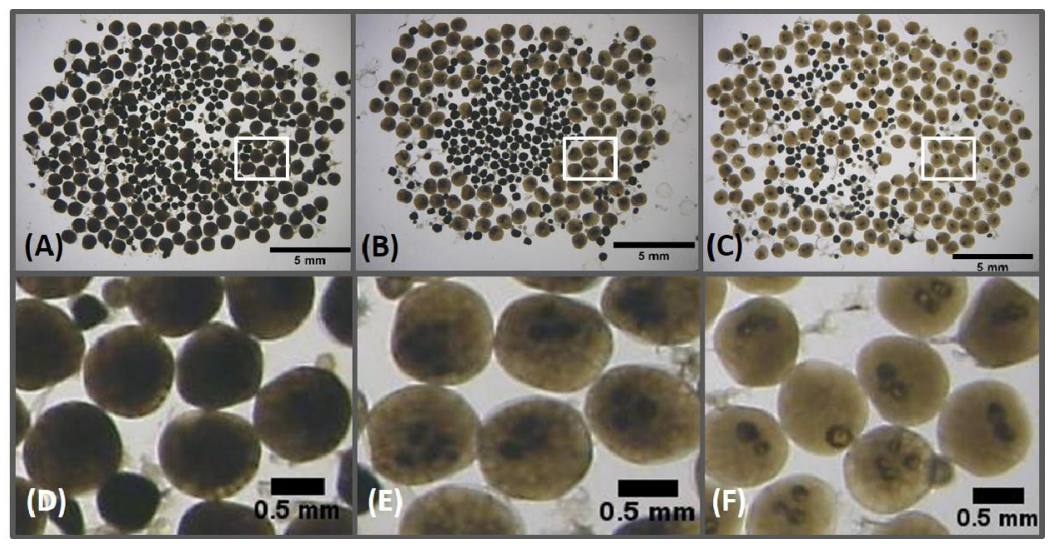

Fig. 3. Whole mount preparations of Atlantic horse mackerel, Trachurus trachurus, ovaries with increasingly translucent hydrated oocytes showing the gradual unveiling of oil droplets. Images in the upper panel show the entire whole mount from ovaries with (A) Opaque oocytes with no visible oil drops (NDRP), and with (B) Semi-translucent and (C) Highly translucent oocytes with visible oil drops (DRP). D-F are magnifications of A-C respectively showing the characteristics of NDRP and DRP oocytes in more detail. Rectangles indicate the position of magnified images.

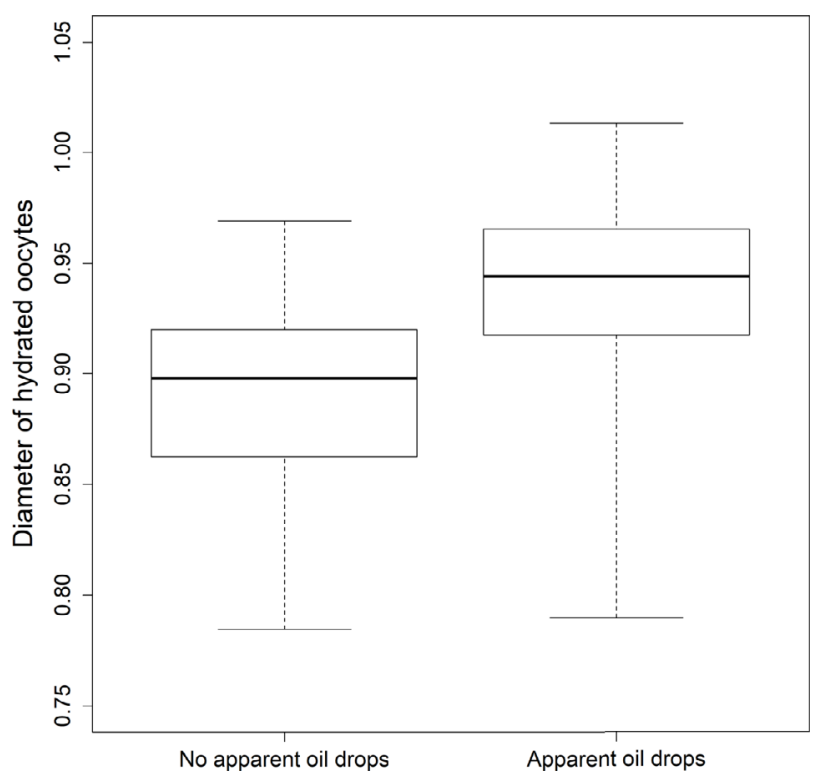

Fig. 4. Atlantic horse mackerel, Trachurus trachurus. Box and whisker plot of mean hydrated oocyte diameters in females with undetectable and visible oil drops. Each box represents the 1st quartile, the median and 3rd quartiles, and whiskers represent the lowest and highest observed values.

Table 2. Coefficients for the final GLM modelling the size of hydrated (HYD) oocytes as a function of sampling time of day and total body length (TL).

\begin{tabular}{lll}
\hline Source of variation & Coefficients & SD \\
\hline Intercept & 5929 & 927 \\
Sampling time of day & $2.68 \times 10^{-6}$ & $0.43 \times 10^{-6}$ \\
TL & $3.06 \times 10^{-3}$ & $1.31 \times 10^{-3}$ \\
\hline
\end{tabular}

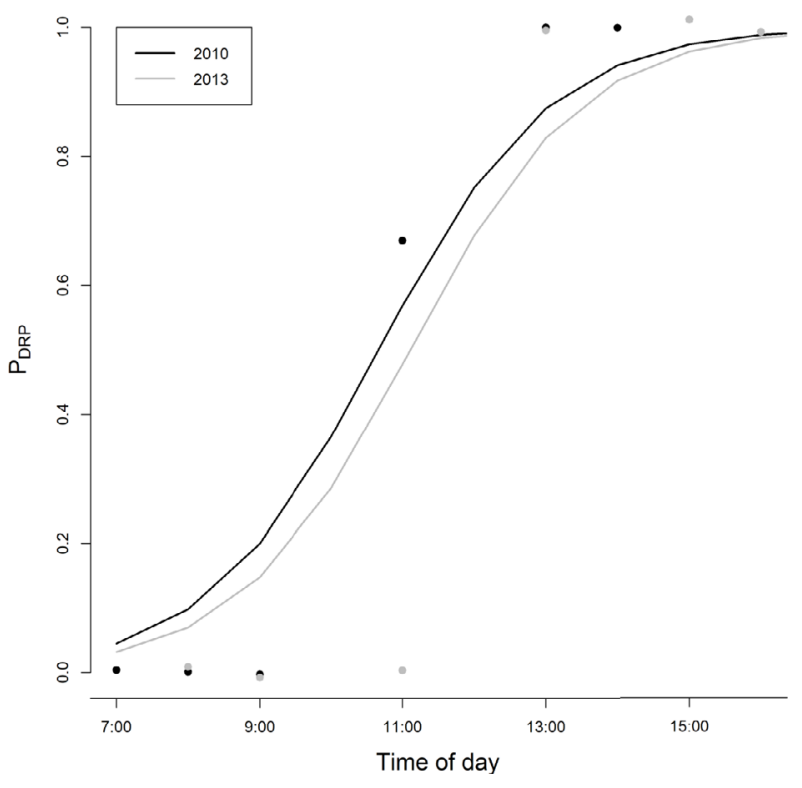

Fig. 5. Atlantic horse mackerel, Trachurus trachurus. GLM fitted relationship between the proportion of hydrated females with visible oil drops $\left(\mathrm{P}_{\mathrm{DRP}}\right)$ and time of day of sampling in 2010 and 2013. Observed $\mathrm{P}_{\mathrm{DRP}}$ (solid circles) are also shown.

(ICES, 2008; Gonçalves et al., 2009; ICES, 2012, 2017). Spawning synchronicity facilitates the correct ageing of POFs for estimations of the spawning fraction and the daily egg production at sea. Up to now this information was only available for anchovy and sardine, the main species the DEPM is being applied to (Stratoudakis et al., 2006). Both species are crepuscular spawners with clear pattern of daily spawning synchronicity (Ganias et al., 2014).

Synchronicity amongst imminent spawners of Atlantic horse mackerel was examined through exploring the diel pattern of two independent aspects of PREF growth: the 

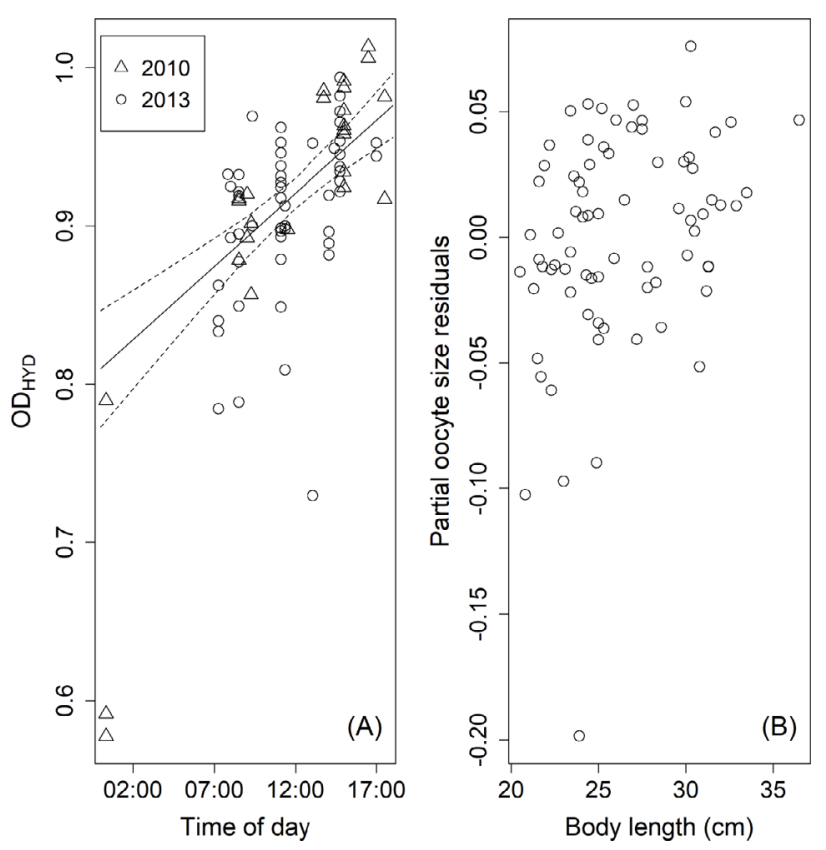

Fig. 6. Atlantic mackerel, Trachurus trachurus. (A) Relationship between hydrated oocytes' size $\left(\mathrm{OD}_{\mathrm{HYD}}\right)$ and sampling hour for the two studied years; least squares line (solid line) and $95 \%$ confidence intervals (dotted lines) are also shown. (B) Relationship between GLM derived partial hydrated oocyte size residuals and body length.

microscopic appearance and the size of maturing oocytes in whole mount preparations. A clear diel pattern was observed in the microscopic appearance of the hydrated oocytes in both studied years (2010 and 2013). The hydrated oocytes turned from highly opaque to translucent which resulted to the appearance of previously indistinguishable oil drops in the ooplasm. The unveiling of oil drops followed a diel pattern which was stable between the two years. Individuals with indistinguishable oil drops (NDRP) prevailed from morning until noon while those with visible oil drops (DRP) were found from noon to late afternoon. The critical time for the shift from the NDRP to DRP state was estimated at around 11:00 a.m. (UTC). This result not only suggests the existence of synchronicity in preovulatory ovarian growth amongst imminent spawners but also that its timing is consistent between years (sampling took place at around the same time of year in both years).

Sometimes the use of preservation fluids other than formalin such as ethanol can cause oocytes to dehydrate and to consequently increase in opacity (Klibansky and Juanes, 2007; Rakka and Ganias, 2015). In the present study all oocytes were preserved in NBF which means changes in oocytes appearance were real rather than methodological artefacts. Increasing translucency and the appearance of oil drops have been also found for oocytes of T. trachurus in the Mediterranean Sea which had been preserved in NBF (Karlou-Riga and Economidis, 1997) and for T. symmetricus off California (Macewicz and Hunter, 1993). These morpho-developmental events were considered to indicate the beginning of the LGVM stage and peak at the late hydration stage. More specifically, in these papers the LGVM oocytes have been described as less opaque than the other yolked oocytes with a wide clearish band on the periphery caused by the fusion of yolked globules and with reflective oil drop(s) in the ooplasm. The observed increase in the translucency and the resulting appearance of oil drops in Atlantic horse mackerel were also clearly related to the hydration process which leads to an increase in the size of hydrated oocytes.

The present study further showed that during both years the size of the hydrated oocytes increased significantly with time of day. Thus, the growth of hydrated oocytes was well synchronized between females capable of spawning during the same spawning season and this pattern was consistent between the two studied spawning seasons. This result corroborates the previous evidence for daily spawning synchronicity in Atlantic horse mackerel for the southern stock. In addition, no females at the LGVM stage and only a few females at the GVBD stage were recorded in the present study. These two stages occur between the onset of the actively spawning sub-phase and hydration (Brown-Peterson et al., 2011). Our samples were mainly collected during daytime (7:00-17:00) while these two stages are expected to occur from late afternoon to the early morning hours. Thus the absence of LGVM females further supports daily synchronicity in Atlantic horse mackerel. Indeed, the only two GVBD females of this study originated from a single sample, captured just after midnight.

In contrast, oocyte size in early germinal vesicle migration ovaries did not exhibit any significant diel patterns, suggesting that this stage is evenly distributed throughout the day - at least during the time frame of our daily sampling period. We also conducted a more in-depth histological investigation of the EGVM stage, through detailed tracking of germinal vesicle dislocation and oil-droplet fusion and polarization, but no pattern was observed with the time of day of sampling. In Ndjaula et al. (2009) captive female Atlantic horse mackerels failed to go on with the actively spawning sub-phase and to hydration and ovarian development ceased at the EGVM stage; the authors attributed this situation to lack of the necessary environmental cues. The histological appearance and the size range of EGVM oocytes in that study agreed with our description of this stage: the germinal vesicle was slightly decentralized, the numerous small oil droplets were still not fused and most of them were gathered at one side of the germinal vesicle (Fig. 2A and C). A similar histological aspect has been described for the EGVM stage of Trachurus mediterraneus (Demirel and Yüksek, 2012). It could thus be assumed that spawning capable horse mackerels grow their oocytes until the EGVM stage and only when the right cue occurs in the environment, e.g. a daylight cue, do they proceed to the actively spawning sub-phase. This is in accordance to the classification of Brown-Peterson et al. (2011) who considered that early stages of FOM can be present at the early developing sub-phase of the spawning capable phase, while LGVM, GVDB and HYD stages belong to the actively spawning sub-phase.

Another important difference between the HYD and EGVM stages is that oocyte size was found to correlate with maternal size in HYD ovaries but not in EGVM ovaries. More specifically, $10 \mathrm{~cm}$ difference in maternal body length corresponded to a $0.030 \mathrm{~mm}$ increase in the diameter of hydrated oocytes. Similarly, Ganias et al. (2015) found for the Atlantic sardine, Sardina pilchardus, that oocyte size was correlated with maternal size in hydrated ovaries but not in vitellogenic ovaries. The authors suggested that the observed 
stage-specific differences of the effect of maternal size on oocyte size were due to a functional relationship between the abdominal volume and ovarian size. Specifically, they showed that the maternal body cavity leaves enough space only for the growth of vitellogenic ovaries but not for the hydrated ovaries, which are very large, reaching the volume limits of the cavity. The body size effect on oocyte size was therefore explained by abdominal volume allometric growth. Given that late vitellogenic and hydrated oocytes in Atlantic horse mackerel (Ganias et al., 2017) exhibit equivalent size ranges to those of Atlantic sardine (Ganias et al., 2011), stage specific constraints of maternal body cavity possibly explain why larger individuals produce larger HYD oocytes but not larger EGVM oocytes than smaller individuals.

\section{Conclusion}

The present study clearly suggests that PREF growth is well synchronized between spawning capable Atlantic horse mackerel which constitutes an important line of evidence for the presence of daily spawning synchronicity in the population. As already mentioned, the latter is quite important for assessment purposes since application of the DEPM for obtaining a biomass index for the assessment of the southern stock is much facilitated when synchronicity is present. However, an important drawback of the present study was that samples originated from outside the daily spawning period since no running females or very recent spawners (females with very early POFs) were recorded. In addition, the very early stages of the actively spawning sub-phase were absent (LGVM) or extremely rare (GVBD), again due to the uncomplete sampling scheme. Thus, a follow-up study that focuses on the full temporal extent of the daily spawning period, the estimation of mean daily spawning time (using eggs and adult information) and the study of diel reproductive phenomena such as courtship behavior and the formation of spawning aggregations is necessary.

Acknowledgements. The authors are grateful to all colleagues, to the crew of the RV "Noruega and to the ship owners and skippers of the bottom trawl fleet that contributed to the collection of the fish samples and/or biological sampling. The authors also acknowledge Carmo Silva Nunes and Paula Abreu for the histological processing, as well as the contribution of Maria Emília Cunha, Alberto Murta and Patrícia Gonçalves during the initial steps for the application of the DEPM to the Atlantic Iberian horse mackerel stock. Three anonymous reviewers are greatly thanked for constructive comments on the manuscript. DEPM surveys are supported by the National Biological Sampling Programme (PNAB)/EU DCF-Data Collection Framework. The work of F.A.M. at IPMA was supported by an Erasmus + for Placements grant and constitutes part of his Master's thesis in AUTH under the supervision of K.G.

\section{References}

Abaunza P, Gordo L, Karlou-Riga C, Murta A, Eltink ATGW, Santamaría MTG, Zimmermann C, Hammer C, Lucio P, Iversen SA, Molloy J, Gallo E. 2003. Growth and reproduction of horse mackerel, Trachurus trachurus (Carangidae). Rev Fish Biol Fish 13: $27-61$.

Alheit J. 1985. Spawning frequency of peruvian anchovies taken with a purse seine, in: R. Lasker (Ed.), An Egg Production Method for Estimating Spawning Biomass of Pelagic Fish: Application to the Northern Anchovy, NOAA Technical Rep NMFS 36, Engraulis Mordax, pp. 99-101.

Basilone G, Ganias K, Ferreri R, D’Elia M, Quinci EM, Mazzola S, Bonanno A. 2015. Application of GAMs and multinomial models to assess the spawning pattern of fishes with daily spawning synchronicity: a case study in the European anchovy (Engraulis encrasicolus) in the central Mediterranean Sea. Fish Res 167: 92-100.

Bernal M, Stratoudakis Y, Wood S, Ibaibarriaga L, Valdes L, Borchers D. 2011. A revision of daily egg production estimation methods, with application to Atlanto-Iberian sardine. 2. Spatially and environmentally explicit estimates of egg production. Ices J Mar Sci 68: 528-536.

Brown-Peterson NJ, Wyanski DM, Saborido-Rey F, Macewicz BJ, Lowerre-Barbieri SK. 2011. A standardized terminology for describing reproductive development in fishes. Mar Coast Fish 3: $52-70$.

DeMartini EE, Fountain RK. 1981. Ovarian cycling frequency and batch fecundity in the queenfish, Seriphus politus: attributes representative of serial spawning fishes. Fish Bull 79: 547-559.

Demirel N, Yüksek A. 2012. Reproductive biology of Trachurus mediterraneus (Carangidae): a detailed study for the MarmaraBlack Sea stock. J Mar Biol Assoc U K 93: 357-364.

Farris DA. 1961. Abundance and distribution of eggs and larvae and survival of larvae of jack mackerel (Trachurus symmetricus). Fish Bull 61: 247-279.

Ganias K. 2008. Ephemeral spawning aggregations in the Mediterranean sardine, Sardina pilchardus: a comparison with other multiple-spawning clupeoids. Mar Biol 155: 293-301.

Ganias K. 2012. Thirty years of using the postovulatory follicles method: overview, problems and alternatives. Fish Res 117-118: 63-74.

Ganias K, Nunes C, Vavalidis T, Rakka M, Stratoudakis Y. 2011. Estimating oocyte growth rate and its potential relationship to spawning frequency in teleosts with indeterminate fecundity. Mar Costal Fish 3: 119-126.

Ganias K, Somarakis S, Nunes C. 2014. Reproductive potential, in: K. Ganias (Ed.), Biology and Ecology of Sardines and Anchovies, CRC Press, Boca Raton, FL, pp. 79-121.

Ganias K, Rakka M, Mantzouki E, Vavalidis T, Tsinganis M, Nunes C. 2015. Maternal versus environmental constraints on the oocyte size of a marine pelagophil fish. Mar Biol 162: $1879-1888$.

Ganias K, Mouchlianitis F-A., Nunes C, Costa A-M., Angélico M-M. 2017. A reassessment of the fecundity type of Atlantic horse mackerel (Trachurus trachurus) in Atlantic Iberian waters (ICES division IXa) shows that indeterminate spawners can cease recruiting oocytes during their spawning season. ICES J Mar Sci J $d u$ Cons 74: 31-400.

Gladstone W. 2007. Selection of a spawning aggregation site by Chromis hypsilepis (Pisces: Pomacentridae): habitat structure, transport potential, and food availability. Mar Ecol Prog Ser 351: 235-247.

Gonçalves P, Costa AM, Murta AG. 2009. Estimates of batch fecundity and spawning fraction for the southern stock of horse mackerel (Trachurus trachurus) in ICES Division IXa. ICES $J$ Mar Sci 66: 617-622. 
Gordo LS, Costa A, Abaunza P, Lucio P, Eltink ATGW, Figueiredo I. 2008. Determinate versus indeterminate fecundity in horse mackerel. Fish Res 89: 181-185.

Hunter JR, Lo NCH, Leong RJH, Leong HJ. 1985. Batch fecundity in multiple spawning fishes, in: R. Lasker (Ed.), An Egg Production Method for Estimating Spawning Biomass of Pelagic Fish: Application to the Northern Anchovy, NOAA Technical Rep NMFS 36, Engraulis Mordax, pp. 67-77.

ICES. 2008. Report of the working group on mackerel and horse mackerel egg surveys (WGMEGS), 7-11 April 2008, ICES Document CM 2008/LRC:09, IJmuiden, Netherlands, 111 p.

ICES. 2012. Report of the working group on mackerel and horse mackerel egg surveys (WGMEGS), 18-21 April 2012, ICES Document CM 2012/SSGESST: 04, Galway, Ireland, 135 p.

ICES. 2017. Final report of the working group on mackerel and horse mackerel egg surveys (WGMEGS), 24-28 April 2017, ICES Document CM 2017/SSGIEOM:18, Vigo, Spain, 136 p.

Karlou-Riga C, Economidis P. 1996. Ovarian atretic rates and sexual maturity of European horse mackerel, Trachurus trachurus (L.) in the Saronikos gulf (Greece). Fish Bull 94: 66-76.

Karlou-Riga C, Economidis PS. 1997. Spawning frequency and batch fecundity of horse mackerel, Trachurus trachurus (L.), in the Saronikos Gulf (Greece). J Appl Ichthyol 3: 97-104.

Klibansky N, Juanes F. 2007. Species-specific effects of four preservative treatments on oocytes and ovarian material of Atlantic cod (Gadus morhua), haddock (Melanogrammus aegleflnus), and American plaice (Hippoglossoides platessoides). Fish Bull 105: 538-547.

Lowerre-Barbieri SK, Ganias K, Saborido-Rey F, Murua H, Hunter JR. 2011. Reproductive timing in marine fishes: variability, temporal scales, and methods. Mar Coast Fish 3: 71-91.

Lubzens E, Young G, Bobe J, Cerdà J. 2010. General and comparative endocrinology oogenesis in teleosts: how fish eggs are formed. Gen Comp Endocrinol 165: 367-389.

Macer CT. 1974. Reproductive biology of horse mackerel Trachurus trachurus (L) in North-Sea and English-Channel. J Fish Biol 6: 415-438.

Macewicz BJ, Hunter JR. 1993. Spawning frequency and batch fecundity of Jack Mackerel, Trachurus symmetricus, off California during 1991. ColCOFl Rep 34: 112-121.
Murta AG, Vendrell C. 2009. Using the EM algorithm to age fish eggs. ICES J Mar Sci 66: 607-616.

Ndjaula HON, Hansen T, Krüger-Johnsen M, Kjesbu OS. 2009. Oocyte development in captive Atlantic horse mackerel Trachurus trachurus. ICES J Mar Sci 66: 623-630.

Priede IG, Watson JJ. 1993. An evaluation of the daily egg production method for estimating biomass of Atlantic mackerel (Scomber scombrus). Bull Mar Sci 53: 891-911.

Rakka M, Ganias K. 2015. Assessing species and stage specific effects of preservation on fish ovarian material over different temporal scales. Mediterr Mar Sci 16: 533-537.

Stratoudakis Y, Bernal M, Ganias K, Uriarte A. 2006. The daily egg production method (DEPM): recent advances, current applications and future challenges. Fish Fish 7: 35-57.

Thorsen A, Fyhn HJ. 1996. Final oocyte maturation in vivo and in vitro in marine fishes with pelagic eggs; Yolk protein hydrolysis and free amino acid content. J Fish Biol 48: 1195-1209.

Thorsen A, Kjesbu OS. 2001. A rapid method for estimation of oocyte size and potential fecundity in Atlantic cod using a computer-aided particle analysis system. J Sea Res 46: 295-308.

Van Damme CJG, Dransfeld L, Eltink ATGW, Krüger-Johnsen M, Pérez JR, Ulleweit J, Witthames PR. 2005. Horse mackerel fecundity in relation to lipid content. ICES CM 2005/Q: 03.

Van Damme CJG, Thorsen A, Fonn M, Alvarez P, Garabana D, O'Hea B, Perez JR, Dickey-Collas M. 2014. Fecundity regulation in horse mackerel. ICES J Mar Sci 71: 546-558.

Wallace RA, Selman K. 1981. Cellular and dynamic aspects of oocyte growth in teleosts. Am Zool 21: 325-343.

Yamahira K. 2001. Experimental examination of interpopulation variation in reproductive timing of a fish. Oecologia 128: 389399.

Zwolinski J, Stratoudakis Y, Soares E. 2001. Intra-annual variation in the batch fecundity of sardine off Portugal. J Fish Biol 58: 1633 1645 .

Cite this article as: Mouchlianitis FA, Nunes C, Costa AM, Angélico MM, Ganias K. 2018. Preovulatory follicle growth dynamics indicates daily spawning synchronicity in wild-caught Atlantic horse mackerel off Portugal. Aquat. Living Resour. 31: 11 